\title{
ADAPTED EUROFIT TESTS: REPRESENTATION OF PHYSICAL DEVELOPMENT OF DIFFERENT AGE CHILDREN GROUPS AT ST. KLIMENT OHRIDSKI PRIVATE PRIMARY SCHOOL - SPEED
}

\author{
D. Peeva* \\ Todor Kableshkov University of Transport, Sofia, Bulgaria
}

\begin{abstract}
The proposed study presents an adapted Eurofit test of speed. It is used to monitor the development of speed in children groups distributed by age. The increase of the indicated quality has been established as a result of the test application during two school years. The reciprocity between age and achievements has been revealed.
\end{abstract}

Key words: physical development, physical quality, speed, test - shuttle run.

\begin{abstract}
INTRODUCTION
Physical education is the only subject that helps for the rehabilitation and integration of students in the family and society after the continuous and complex learning process at secondary schools. To a great extent, the success in achieving the main purpose of physical education depends on the teacher's professionalism and learners' positive attitude to tasks assigned. This attitude is corrected with the application of innovative and adaptive approaches to the traditional methods of obtaining high results.
\end{abstract}

The purpose of study was to determine physical condition (baseline level) and physical development (end-of-the-school-year test) of children at primary and secondary schools under the condition of private schools and by examining the changes of two physical qualities. Two tests were chosen - for speed and explosive force, each being a subject of separate survey. The current study is devoted to speed.

Speed is the person's ability to move with great speed and frequency for a minimum period of time (1). The theory marks four

*Correspondence to: Diana Peeva, Todor

Kableshkov University of Transport, 158 Geo Milev

Street, Sofia,Bulgaria,e-maildiana2616@abv.bg relatively separate forms of speed but this paper focuses on the form aimed at overcoming a certain distance for the shortest possible time.

The object of this survey was children aged 613 who had been divided into 2 groups: 6-8year-old children including 78 participants (of which 35 boys and 43 girls) and 10-12-yearold students including 51children (of which 28 boys and 23 girls). A separate analysis was made by the sex of participants. (It is imperative to keep in mind the turnover of students during the school year and moving from one to another class as well as the increase of children's age!)

The study duration was 2 school years but due to objective reasons, it was reduced to 3 learning periods (instead of 4).

The survey tasks were as follows:

- establishment of the students' baseline level;

- monitoring on the learning process outcomes at the end of the school year;

- determination of change: positive or negative within the scores during the entire school year and a baseline test at the beginning of the next school year.

\section{METHODS}

The methodology applied to the study on speed was an adapted Eurofit test - shuttle run (2). Under this study, it had been complicated with 
an element of spatial orientation since the conditions of this test performance allowed to do that. The adapted presentation of traditional tests had been made on an innovative purpose related to the increase of interest in athletics as
PEEVA D.

well as to children's responsibility and pleasure to perform the tasks assigned to them. The adapted shuttle test can be conditionally called "Polygon Snake" - Figure 1.

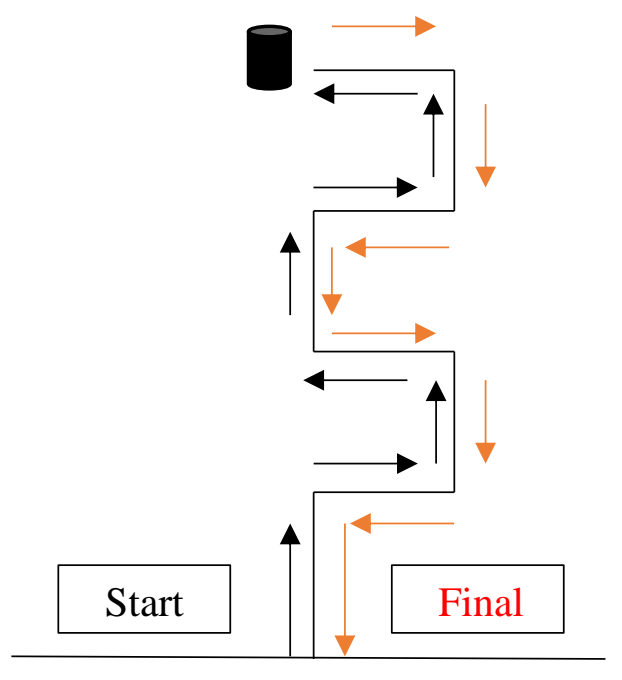

Figure 1. Model of "Polygon Snake"

Unlike with the shuttle sprint, the route was built with a few changes of direction with turns of $90^{\circ}$ where the segments between them were equal - 3 meters long; the initial straight line was slightly longer -4 meters long - in order to collect speed. The participants passed the route and, touching the end point, returned to the start-final segment along the same road. The total distance was $50 \mathrm{~m}$ and the test was carried outdoor only once.

\section{RESULTS AND DISCUSSION:}

The results of the study are presented in tabular form in Tables 1-5.

Table 1. Baseline test results of 6-8-year-olds in 2018/2019 school year (in sec)

\begin{tabular}{|l|l|l|l|l|l|l|l|l|l|l|l|}
\hline \multicolumn{1}{|c|}{$\begin{array}{c}\text { SI } \\
\text { Year }\end{array}$} & $\mathbf{N}$ & $\mathbf{X}_{\mathbf{m}}$ & $\mathbf{X}_{\text {max }}$ & $\mathbf{X}_{\text {min }}$ & $\mathbf{D}$ & Direction & $\mathbf{N}$ & $\mathbf{X}_{\mathbf{m}}$ & $\mathbf{X}_{\text {max }}$ & $\mathbf{X}_{\text {min }}$ & $\mathbf{D}$ \\
\hline $\mathbf{6}$ & 7 & 23 & 26 & 21 & 5 & - & 13 & 25 & 27 & 23 & 4 \\
\hline $\mathbf{7}$ & 8 & 23.5 & 27 & 21 & 6 & - & 12 & 25.3 & 27 & 22 & 5 \\
\hline $\mathbf{8}$ & 20 & 22.3 & 26 & 18 & 8 & - & 18 & 23.5 & 27 & 20 & 7 \\
\hline
\end{tabular}

It can be monitored that there was an increase of the test performance time of 7-year-old boys, which directly corresponds to the results obtained by other sports surveys indicating that 6- and 8-year-olds achieve better reactivity in speed tests. At the same time differences of the lowest scores are very close. The direction of increase in speed tests is negative as the better score corresponds to a lower value. The girls' performance under the survey was lower throughout all years, both with the average and maximum and minimum values, but the differences were smaller, which suggests a more homogeneous group.

Table 2. End-of-the-year test results of 6-8-year-olds in 2019 (in sec)

\begin{tabular}{|l|l|l|l|l|l|l|l|l|l|l|l|}
\hline \multicolumn{1}{|c|}{$\begin{array}{c}\text { SI } \\
\text { Year }\end{array}$} & $\mathbf{N}$ & $\mathbf{X}_{\mathbf{m}}$ & $\mathbf{X}_{\text {max }}$ & $\mathbf{X}_{\text {min }}$ & $\mathbf{D}$ & Direction & $\mathbf{N}$ & $\mathbf{X}_{\mathbf{m}}$ & $\mathbf{X}_{\text {max }}$ & $\mathbf{X}_{\text {min }}$ & $\mathbf{D}$ \\
\hline $\mathbf{6}$ & 7 & 22,8 & 25 & 21 & 4 & - & 13 & 24,7 & 26 & 23 & 3 \\
\hline $\mathbf{7}$ & 8 & 23,4 & 26 & 21 & 5 & - & 12 & 25 & 27 & 22 & 5 \\
\hline $\mathbf{8}$ & 20 & 21,2 & 24 & 19 & 5 & - & 18 & 22,8 & 24 & 19 & 5 \\
\hline
\end{tabular}


After the analysis it can be concluded that the tendency to improve scores at the age of 8 continued while at the same time the differences between final achievements decreased. Further clarification of this little score improvement lies on the fact that the test was a "snapshot" of speed state and any purposeful work, out of the general work in classes, had not been done in order to increase the test results.

The study continued on the following school year but the changes of participants due to the great mobility of children must be taken into account. Thus, the first group consisting of the former 6-year-olds, already included 15 boys and there were no changes in the other two groups. The difference with girls was in the group of oldest, namely that of 9-year-olds who from 18 became 15 . This clarification is necessary as the new students tend to orientate themselves more slowly in unfamiliar environment and with the requirements of teachers.

Table 3. Baseline test of 7-9-year olds in 2019/2020 school year (in sec)

\begin{tabular}{|l|l|l|l|l|l|l|l|l|l|l|l|}
\hline \multicolumn{1}{|c|}{$\begin{array}{c}\text { SI } \\
\text { Year }\end{array}$} & $\mathbf{N}$ & $\mathbf{X}_{\mathbf{m}}$ & $\mathbf{X}_{\text {max }}$ & $\mathbf{X}_{\text {min }}$ & $\mathbf{D}$ & Direction & $\mathbf{N}$ & $\mathbf{X}_{\mathbf{m}}$ & $\mathbf{X}_{\max }$ & $\mathbf{X}_{\text {min }}$ & $\mathbf{D}$ \\
\hline $\mathbf{7}$ & 15 & 23,2 & 25 & 21 & 4 & - & 13 & 24,3 & 27 & 23 & 4 \\
\hline $\mathbf{8}$ & 8 & 21,1 & 24 & 17 & 7 & - & 12 & 23,8 & 26 & 22 & 4 \\
\hline $\mathbf{9}$ & 20 & 21,8 & 25 & 19 & 6 & - & 15 & 23,5 & 25 & 20 & 5 \\
\hline
\end{tabular}

The highest increase of scores was noted with students aged 7-8, with a peak at the age of 8 where the improvement was more than 2 secs with boys and over 1 second with girls. The tendency noted at the age between 8 and 9 was of detention and even of a certain drop in the scores of boys while the scores of girls remained stable. The reasons lie mostly in psychophysical abilities at that age.

Table 4. Baseline test results of 10-12 year-olds in 2018/2019 school year (in sec)

\begin{tabular}{|l|l|l|l|l|l|l|l|l|l|l|l|}
\hline \multicolumn{1}{|c|}{ BI } \\
$\begin{array}{c}\text { Sear } \\
\text { 10 }\end{array}$ & $\mathbf{N}$ & $\mathbf{X}_{\mathbf{m}}$ & $\mathbf{X}_{\text {max }}$ & $\mathbf{X}_{\text {min }}$ & $\mathbf{D}$ & Direction & $\mathbf{N}$ & $\mathbf{X}_{\mathbf{m}}$ & $\mathbf{X}_{\text {max }}$ & $\mathbf{X}_{\text {min }}$ & $\mathbf{D}$ \\
\hline $\mathbf{1 1}$ & 9 & 20,3 & 23 & 18 & 5 & - & 8 & 22,3 & 24 & 18 & 6 \\
\hline $\mathbf{1 2}$ & 7 & 22,2 & 24 & 19 & 5 & - & 10 & 22,5 & 26 & 20 & 6 \\
\hline
\end{tabular}

The analysis has shown that of all who participated in the survey, the 10-year-old boys and girls were the fastest runners. Compared to the "junior group" in the same period, the differences for both sexes were almost 3 seconds. That correlates with the period of adolescents' development when speed as a physical quality develops at a high rate.

Table 5. End-of-the-year test results of 10-12-year olds in 2019 (in sec)

\begin{tabular}{|l|l|l|l|l|l|l|l|l|l|l|l|}
\hline \multicolumn{1}{|c|}{ BI } \\
$\begin{array}{c}\text { SI } \\
\text { Year }\end{array}$ & $\mathbf{N}$ & $\mathbf{X}_{\mathbf{m}}$ & $\mathbf{X}_{\text {max }}$ & $\mathbf{X}_{\text {min }}$ & $\mathbf{D}$ & Direction & $\mathbf{N}$ & $\mathbf{X}_{\mathbf{m}}$ & $\mathbf{X}_{\text {max }}$ & $\mathbf{X}_{\text {min }}$ & $\mathbf{D}$ \\
\hline $\mathbf{1 0}$ & 12 & 20,6 & 24 & 19 & 5 & - & 8 & 22,8 & 25 & 20 & 5 \\
\hline $\mathbf{1 1}$ & 9 & 23,2 & 26 & 21 & 5 & - & 10 & 23,1 & 26 & 20 & 6 \\
\hline $\mathbf{1 2}$ & 7 & 23,8 & 27 & 22 & 5 & - & 5 & 23,7 & 26 & 21 & 5 \\
\hline
\end{tabular}

The end-of-the-year test of "the senior group" included in this study showed a smooth drop of girls' scores with the increase of their age and significantly sharper fall of the boys. The reason can be explained again with the physiological peculiarities of the respective sex at that age.
During the school year 2019/2020, the study faced objective difficulties due to a significant change of the number of participants who for various reasons became only 35 of 53 children in all three grades. There were only 3 girls in the group of 13-year-olds, so these three girls could not represent proper statistical results. 
Unfortunately, that was the reason to discontinue the study.

\section{CONCLUSIONS}

The conclusions and recommendations, which can be drawn from this study, although incomplete, are as follows:

- it was found that the results of the modified speed test had improved with the age increase in both groups, the increase being most significant up to the age of 10 ;

- after this "peak" at the age of 10 there was a gradual decrease of results, which appeared to be less with girls;

- the emotional charge of participants during the tests was not a subject of statistical prove but the active involvement of all students in the experiment, the pleasure of participation and increased scores proved the adequacy and effectiveness of innovation applied;

- the conclusions and scores as well as the subjective positive experience of students can be interpreted as a kind of recommendation to include the new test in methodology for speed assessment of students at primary and secondary schools.

\section{REFERENCES}

1. Rachev, K., Theory and Methods of Physical Education, Sofia, 1984

2. 2.Oja, P. (Author), Tuxworth, B. (Editor), Eurofit for Adults: Assessment of HealthRelated Fitness, CE, 1995) 